\title{
Research Communication Interleukin 6 and 8 Levels in Plasma and Fibroblast Cultures in Psoriasis
}

\author{
Anna Zalewska, ${ }^{1}$ Ewa Głowacka, ${ }^{2}$ Janina Wyczółkowska, ${ }^{3}$ Henryk Tchórzewski, ${ }^{2}$ \\ Joanna Narbutt, ${ }^{1}$ and Anna Sysa-Jȩdrzejowska ${ }^{1}$ \\ ${ }^{1}$ Department of Dermatology and Venereology, Medical University of Łódź, 5 Krzemieniecka Street, 94-017 Łódź, Poland \\ ${ }^{2}$ Department of Clinical Immunology, Polish Mother's Memorial Hospital-Research Institute, 93-338 Łódź, Poland \\ ${ }^{3}$ Centre for Medical Biology, Polish Academy of Sciences, 93-232 Łódz, Poland
}

Received 21 September 2005; Accepted 20 October 2005

\begin{abstract}
Fibroblasts have been implicated in psoriatic inflammatory processes. The aim of the study was to evaluate soluble interleukin 2 receptor (sIL-2R), interleukin 6 (IL-6), and interleukin 8 (IL-8) plasma levels in psoriatic patients and IL-6 and IL-8 levels in fibroblast culture supernatants. Cytokines levels in plasma and supernatants were measured by ELISA. Plasma sIL-2R, IL-6, and IL8 levels were higher before the treatment in comparison to healthy controls $(P<0.001)$ and decreased after treatment. Fibroblasts from healthy controls, psoriatic lesional skin, and noninvolved psoriatic skin, when stimulated with tumor necrosis factor alpha, released considerable amounts of IL-6 and IL-8. No significant difference between healthy controls and psoriatic fibroblasts was observed. Monitoring plasma sIL-2R levels could be employed as a reliable method of psoriasis activity. IL-8 and IL-6 plasma levels seem to reflect psoriasis activity, and treatment response, respectively. Fibroblasts are not a major source of increased IL-6 and IL-8 production in psoriasis.
\end{abstract}

Copyright (c) 2006 Anna Zalewska et al. This is an open access article distributed under the Creative Commons Attribution License, which permits unrestricted use, distribution, and reproduction in any medium, provided the original work is properly cited.

\section{INTRODUCTION}

Psoriasis is a chronic recurrent skin disease involving $1 \%$ to $2 \%$ of human population worldwide. On histology, it is characterized by hyperproliferation of keratinocytes, vascular expansion, together with leukocyte infiltration. It is widely accepted that genetic predisposition and environmental factors have a profound effect on the immune system and play a crucial role in triggering psoriatic lesion development. Psoriasis is regarded as a $\mathrm{T}_{\mathrm{H}^{1}}$ disorder of autoimmune background and it is postulated that changes in cytokine production both locally and systemically could be useful in monitoring activity of the disease [1-4].

Fibroblasts are the most abundant cells in the connective tissue. From the historical point of view, these cells were regarded as only quiescent elements forming stromal framework for other cells in the connective tissue [5]. Not long ago, fibroblasts were discovered to initiate the earliest molecular events, thus leading to inflammatory responses [6]. So, in view of current findings, fibroblasts should be regarded as active participants of tissue reactivity taking part in inflammatory and remodelling processes. Literature data point out fibroblast involvement in psoriatic inflammation $[7,8]$.
Interleukin 6 (IL-6) is a pleiotropic cytokine. Among its characteristic actions are regulation of expression of other cytokines, induction of differentiation and proliferation of normal and malignant cells, inhibition of tumor growth. IL6 is also regarded as a major inducer of the acute-phase response [9]. IL-6 is a component of normal human skin and it was immunologically detected in basal keratinocytes, endothelial cells, many mononuclear cells, fibroblasts, and sudoriparous ducts [10]. IL-6 has been suggested to function as an autocrine mitogen in psoriatic epidermis [11]. In psoriasis, intense labelling of the cytoplasm in the vicinity of keratinocytes membranes was detected in the epidermal layers and other skin appendages. Bearing in mind that this interleukin acts synergistically with IL-1 and tumor necrosis factor alpha (TNF- $\alpha$ ) further supports the hypothesis that IL-6 may contribute via its receptor action to epidermal growth factor (EGF) function in modulating cell hyperproliferation in psoriasis [10].

Interleukin 8 (IL-8) is the best-known chemokine. Its action is greatly enhanced by IL- 1 and TNF- $\alpha$. IL- 8 exerts a very strong chemotactic activity towards neutrophils [12]. Gearing et al studying different cytokine levels, that is, IL-2, IL-4, IL-6, IL-8, GM-CSF (granulocyte/macrophage colonystimulating factor) in aqueous extracts of stratum corneum 
from psoriatic lesions and normal heel, found out that IL8 was the only biologically active cytokine to be elevated in psoriatic lesional extracts [13].

The aim of the study was to evaluate sIL-2R, IL-6, and IL8 plasma levels in psoriatic patients and Il-6 and IL-8 levels in fibroblast cultures.

\section{MATERIALS AND METHODS}

The study comprised 106 patients (30 females, 76 males), aged $19-79$ years (mean $44.9 \pm 13.6$ years) hospitalized at the Department of Dermatology and Venereology, Medical University of Łódź, because of psoriasis vulgaris of moderateto-severe course. The control group comprised 40 healthy volunteers (17 females, 23 males), aged 22-69 years (mean $46 \pm 13.5$ years). Psoriatic patients presented an active disease and the last exacerbation lasted from 2 to 8 weeks (mean $4 \pm 1.6$ weeks). The patients took only emollients and keratolytic drugs before admittance to hospital. As for comorbidity, hypertension was the most often discovered in psoriasis patients (52 out of 106), then diabetes type II (7 out of 106), and peptic ulcer (4 out of 106).

Blood was collected into pyrogen-free EDTA tubes in the morning of the second day after admittance to hospital and 3 weeks after inpatient treatment, centrifuged within $30 \mathrm{~min}-$ utes of collection (at $1000 \mathrm{xg}$ ), and plasma was frozen in $-70^{\circ} \mathrm{C}$ until further evaluated.

On the days of blood collection, clinical severity of the disease was evaluated by PASI score (range 1-72 points) [14, 15]. Before inpatient treatment, PASI ranged from 7.2 to 29.8 (mean $16.7 \pm 5.7$ ), and 3 weeks thereafter ranged from 2.8 to 19.5 (mean $9.3 \pm 4.1$ ).

In hospital, the following treatment methods were employed: Ingram method (ie, anthralin plus UVB-NB irradiation: $311 \mathrm{~nm}$, total cumulative dose mean $17.3 \mathrm{~J} / \mathrm{cm}^{2}$ ) received by 58 patients, anthralin alone received by 10 patients, Goeckerman method (ie, tar plus UVB-NB irradiation: $311 \mathrm{~nm}$, total cumulative dose mean $18.5 \mathrm{~J} / \mathrm{cm}^{2}$ ) received by 10 patients, methotrexate (total dose mean $27.5 \mathrm{mg}$ administered orally) received by 28 patients.

In psoriasis vulgaris patients, a $3 \mathrm{~mm}$ punch biopsy was taken from a representative psoriatic lesion located on the external surface of the forearm from the plaque centre and from perilesional noninvolved skin situated about $4-5 \mathrm{~mm}$ visible by the naked eye psoriatic plaque edge. In the control group, biopsies were taken once from the normal skin of the forearm. The tissue was digested with $0.25 \%$ collagenase and $0.05 \%$ deoxyribonuclease I (Sigma BioSciences, St Louis, Mo, USA) in $1 \mathrm{~mL}$ MEM (Biomed, Lublin, Poland) supplemented by $20 \%$ foetal calf serum (FCS; Hungarpol, Warsaw, Poland), $25 \mathrm{mM}$ HEPES, $2 \mathrm{mM}$ L-glutamine, 100 units/mL of penicillin, and $100 \mu \mathrm{g} / \mathrm{mL}$ of streptomycin (complete MEM, all from Sigma BioSciences, St Louis, Mo, USA), at $37^{\circ} \mathrm{C}$ for 24 hours. Cells released during tissue digestion were transferred to tissue culture flasks supplemented with $5 \mathrm{~mL}$ of complete MEM and cultured in $\mathrm{CO}_{2}$ incubator. The medium was changed twice a week until confluent fibroblast cultures were obtained. Cells of passages 3 to 4 were used for the current study. Three different populations of fibroblasts were used: from normal skin of the healthy controls, from lesional skin of psoriatic patients (psoriatic skin), and from perilesional skin of psoriatic plaques (noninvolved psoriatic skin). Fibroblasts $\left(10^{5}\right.$ cells $\left./ \mathrm{mL}\right)$ were incubated with either TNF- $\alpha$ $(10 \mathrm{ng} / \mathrm{mL})$ or IL-8 $(0.1 \mu \mathrm{g} / \mathrm{mL})$ for 6 hours, washed in culture medium and subsequently suspended in it, and further incubated in pure culture medium for 21 hours when supernatants were collected and frozen in $-70^{\circ} \mathrm{C}$ until further evaluated.

In plasma sIL-2R, IL-6, and IL-8 and in supernatants, IL6 and IL- 8 were assessed by ELISA method (sIL-2R by Endogen kits-Pierce Biotechnology, Inc., Rockford, Ill, USA; IL- 6 and IL- 8 by OptEIA Sets-Pharmingen, BD Biosciences, San Jose, Calif, USA) according to the manufacturers instructions.

All the patients and individuals participating in the study gave their informed consent according to the Medical University of Łódź Bioethic Committee requirements.

\section{STATISTICAL ANALYSIS}

The obtained results were expressed as minimal and maximal values (range) and median value $(\mathrm{Me})$. Numerical variables distribution was assessed by $\lambda$-Kolmogorow test. Comparisons between groups were performed using Mann-Whitney and Pearson correlation coefficient $(r)$. A $P$ value less than 0.05 was considered to be statistically significant.

\section{RESULTS}

\section{Plasma measurements}

We observed significantly increased plasma sIL-2R and IL6 levels before treatment than 3 weeks after inpatient treatment and also when comparing with the healthy controls (both $P<0.001$ ). No significant differences in the above cytokine plasma levels were found between psoriatic patients after treatment and healthy controls $(P>0.05)$. IL-8 plasma levels before treatment were also significantly higher than after treatment $(P<0.01)$ and in comparison to healthy controls $(P<0.001)$. Still after 3 weeks of treatment in psoriatic patients, IL-8 plasma levels were significantly higher than in the healthy controls $(P<0.01)$ (Table 1$)$.

Analysis of correlations between clinical parameters such as sex, age of the patients, and their disease development, time of the last exacerbation, PASI score, and sIL-2R, IL-6, and IL- 8 was performed. Both before and after treatment, there was a positive correlation between sIL-2R and PASI score $(r=0.69, P<0.001$, and $r=0.75, P<0.001$, resp) (Figure 1). Also a positive correlation was observed between age of the patients and sIL-2R plasma levels after the treatment $(r=0.22, P<0.01)$.

Next, before treatment, a positive correlation between plasma IL-8 levels and PASI score was observed $(r=0.25$, $P<0.01)$. Additionally, also a positive correlation, however, after treatment between plasma IL- 6 and PASI score was found ( $r=0.19, P<0.05)$. What is more, before treatment, 
TABLE 1: Comparison of sIL-2R, IL-6, and IL-8 levels in plasma of psoriasis vulgaris patients before treatment and three weeks thereafter compared with healthy controls.

\begin{tabular}{|c|c|c|c|c|c|}
\hline \multirow[b]{2}{*}{ Parameter } & \multirow{2}{*}{$\begin{array}{l}\text { Statistical } \\
\text { parameters }\end{array}$} & \multicolumn{2}{|c|}{ Psoriatic patients } & \multirow{2}{*}{$\begin{array}{l}\text { Healthy } \\
\text { controls (c) }\end{array}$} & \multirow[b]{2}{*}{$P$ level } \\
\hline & & $\begin{array}{l}\text { Before treatment } \\
\text { (a) }\end{array}$ & $\begin{array}{l}\text { After } 3 \text { weeks of } \\
\text { treatment (b) }\end{array}$ & & \\
\hline \multirow{2}{*}{$\begin{array}{l}\text { sIL-2R } \\
(\mathrm{pg} / \mathrm{mL})\end{array}$} & range & $203-8103$ & $104-7851$ & $437-2101$ & \multirow{2}{*}{$\begin{array}{l}\text { (a)-(b) } P<0.001 \\
\text { (a)-(c) } P<0.001 \\
\text { (b)-(c) } P>0.05\end{array}$} \\
\hline & $\mathrm{Me}$ & 2166 & 1103 & 897 & \\
\hline \multirow{2}{*}{$\begin{array}{l}\text { IL-6 } \\
(\mathrm{pg} / \mathrm{mL})\end{array}$} & range & $0-305$ & $0-74$ & $0-7$ & \multirow{2}{*}{$\begin{array}{l}\text { (a)-(b) } P<0.001 \\
\text { (a)-(c) } P<0.001 \\
\text { (b)-(c) } P>0.05\end{array}$} \\
\hline & $\mathrm{Me}$ & 4 & 1 & 1 & \\
\hline \multirow{2}{*}{$\begin{array}{l}\text { IL-8 } \\
(\mathrm{pg} / \mathrm{mL})\end{array}$} & range & $0-20$ & $0-11$ & $0-1$ & \multirow{2}{*}{$\begin{array}{l}\text { (a)-(b) } P<0.001 \\
\text { (a)-(c) } P<0.001 \\
\text { (b)-(c) } P<0.01\end{array}$} \\
\hline & $\mathrm{Me}$ & 2 & 0 & 0 & \\
\hline
\end{tabular}

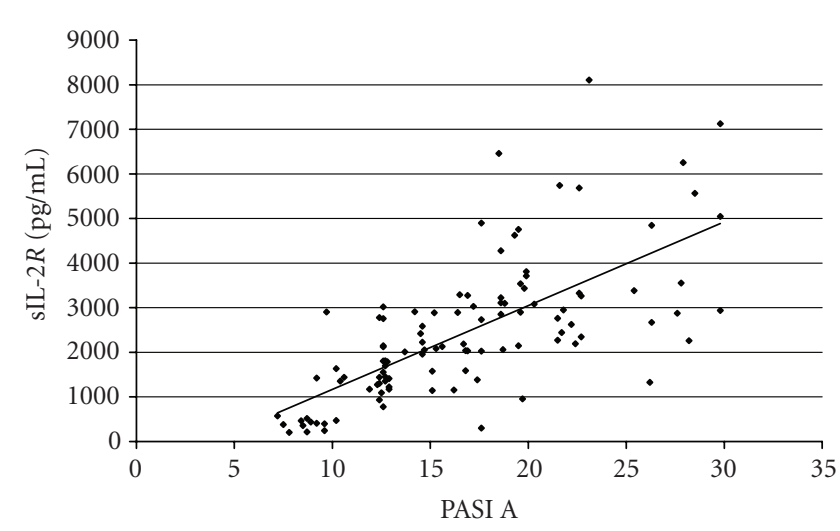

(a)

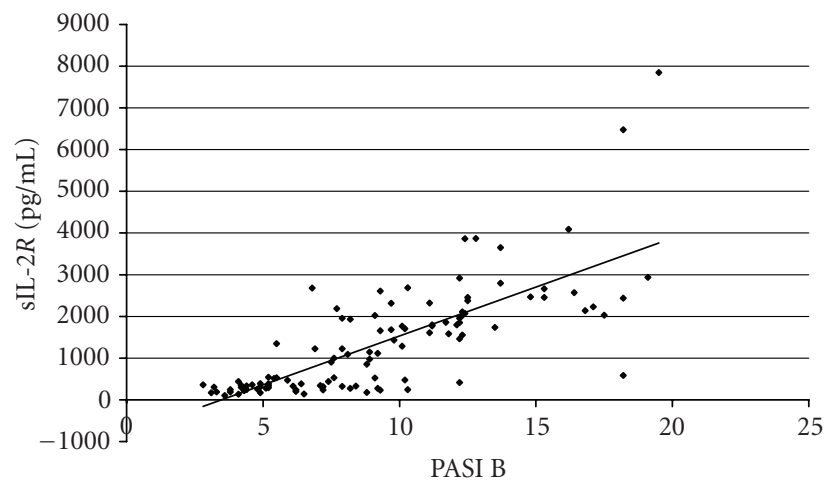

(b)

FIGURE 1: Correlation between sIL-2R plasma levels and PASI score before (PASI A) and after (PASI B) the treatment ( $y$ represents linear regression equation; $R^{2}$ represents determination coefficient): (a) PASI A, $y=187.77 x-708.51, R^{2}=0.4725$; (b) PASI B, $y=234.67 x-$ $814.12, R^{2}=0.5604$.

also a positive correlation between sIL-2R and IL-8 plasma levels was discovered $(r=0.23, P<0.05)$.

\section{Fibroblast cultures}

Stimulation by either IL- 8 or TNF- $\alpha$ caused huge production of IL- 8 by all types of fibroblasts in comparison to baseline conditions $(70-100$ times greater $)(P<0.001)$. Also stimulation with TNF- $\alpha$ led to considerable increase (10-20 times) in IL-6 release by all fibroblast populations in comparison to baseline and IL-8 stimulation $(P<0.001)$ (Table 2$)$.

At baseline, healthy controls fibroblasts released significantly higher amounts of IL-6 than noninvolved psoriatic skin fibroblasts $(P<0.05)$. When stimulated with IL-8, no statistically significant difference in IL-6 release was observed between all the studied fibroblast cultures. However, when stimulated with TNF- $\alpha$, healthy controls fibroblasts released increased amounts of IL- 6 in comparison to noninvolved psoriatic skin fibroblasts $(P<0.05)$.

At baseline, no statistically significant differences in IL8 release were observed between all types of fibroblasts.
However, when stimulated with IL- 8 or TNF- $\alpha$, noninvolved psoriatic skin fibroblasts released significantly lower amounts of IL-8 than both psoriatic skin fibroblasts and healthy controls fibroblasts $(P<0.05)$ (Table 2$)$.

\section{DISCUSSION}

Interaction between $\mathrm{T}$ cells and keratinocytes is important in pathogenesis of psoriasis by secretion of proinflammatory cytokines and growth factors in psoriatic skin. Cellular receptor for IL-2 is expressed on activated T cells and can be shed from the cells and measured as a soluble protein (sIL2R) [16]. Several cytokines have been increased in psoriasis, either at local or systemic level or both including TNF- $\alpha$, IL2, IL-6, IL-8, interferon gamma (IFN- $\gamma$ ), and transforming growth factor alpha (TGF- $\alpha$ ) which are regarded as hallmark cytokines in psoriatic cytokine network [4, 7, 17-19]. For decades, fibroblasts seemed to be only "reserved" to active participation in fibrotic processes. Nowadays however, it is postulated that these cells could actively participate in many immunological processes including inflammation. However, 
TABLE 2: Comparison of IL-6 and IL-8 levels in supernatants obtained from cultures of different types of fibroblasts. (a) Healthy controls: fibroblasts from normal skin of healthy volunteers; (b) psoriatic skin: fibroblasts from lesional skin of psoriatic patients; (c) noninvolved psoriatic skin: fibroblasts from perilesional skin of psoriatic patients.

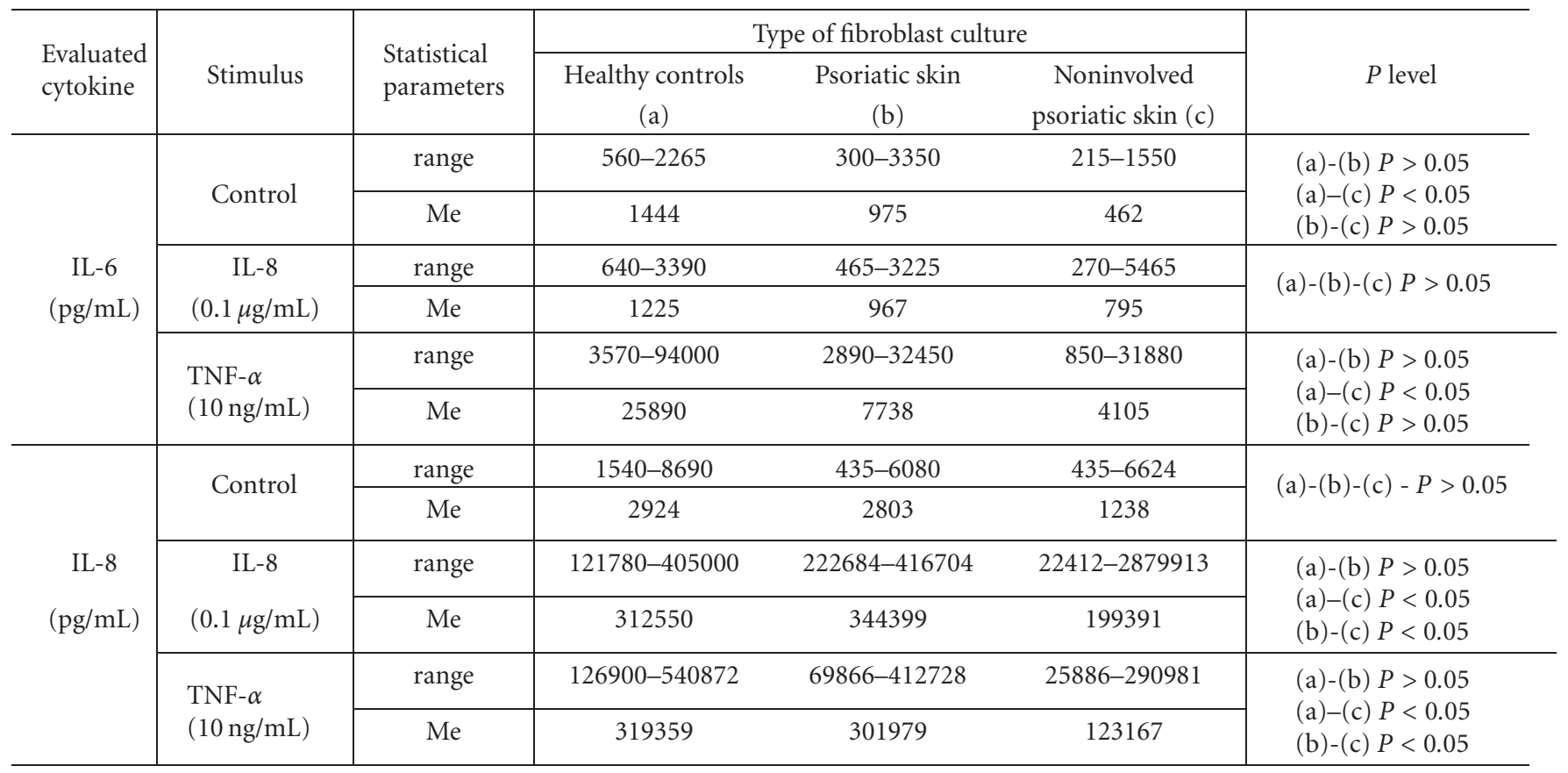

some reports deal with a possible involvement of fibroblasts in the development of this disease [7, 8, 20-22].

In our group of patients, plasma sIL-2R, IL-6, and IL8 levels were significantly increased when comparing with healthy controls, and subsequently they fell down parallel with successful treatment in all the treatment groups. Our results are in line with previous reports [23-33], but some authors argue that isolated topical antipsoriatic treatment is unable to lead to systemic changes [16]. However, Naldi reported that conventional therapies despite being widely used for decades, have not been thoroughly studied [34].

So, it seemed quite reasonable to examine plasma sIL-2R, IL-6, and IL-8 levels and their correlation with different clinical parameters on quite numerous group of psoriasis vulgaris patients. In our study, plasma sIL-2R levels, both before and after inpatient treatment, correlated in a positive way with PASI. Also we demonstrated a positive correlation between age of the patients and plasma sIL-2R levels after treatment. This could result to some extent from the observation that the older the age of the patients, the longer duration of the disease and maybe similar pattern of response as regards disease activity evaluation. Thus, the older the patients, the higher plasma sIL-2R levels after successful antipsoriatic treatment. Plasma sIL-2R levels could be regarded as a marker of treatment response in psoriatic patients and employed in clinical practice.

Literature data point out increased serum IL-6 and IL8 levels in psoriasis [11,35-38]. Some of the reports also demonstrate that either lesional or serum levels of these cytokines reflect to some extent disease activity and treatment response $[12,39,40]$. In our group, a positive correlation between plasma sIL-2R and IL-8 levels before treatment was demonstrated suggesting that IL- 8 could be regarded as an additional, apart from sIL-2R, indicator of psoriasis activity. We also observed a positive correlation between plasma IL-6 and sIL-2R levels after treatment. These results seem to point out IL-6 as an indicator of treatment response.

Debets et al, studying normal and psoriatic fibroblasts and their secretion of IL-1, IL-6, IL- 8 , and TNF- $\alpha$, concentrated on culture conditions, and discovered that FCS, inactivated FCS, and human serum completely inhibited the expression of IL-6 mRNA in all lesional psoriatic fibroblasts [8]. The authors discovered that psoriatic and normal fibroblasts produced negligible amounts of IL- 1 and TNF- $\alpha$. Psoriatic fibroblasts secrete low but increased amounts of IL-6 compared to normal fibroblasts under serum-free conditions and production of IL- 8 was comparable to that of IL- 6 . The authors discovered that TNF- $\alpha$ stimulation leads to considerable IL- 6 release by normal fibroblasts and much less pronounced release of IL-8. Our experiments, however, show that stimulation of IL-8, which is abundantly expressed in psoriatic lesions and acts as a very strong chemoattractant towards neutrophils gathered in psoriatic lesions, caused a huge release of IL- 8 by all types of fibroblast. This could suggest that fibroblasts per se are very sensitive to this cytokine and are able to further release IL- 8 in an autocrine manner. Also stimulation with TNF- $\alpha$ led to huge response in IL-8 release by all the studied fibroblast populations.

The obtained results demonstrated that stimulation of fibroblasts with either IL- 8 or TNF- $\alpha$ could lead to potentiation of inflammatory response. If we take a try to extrapolate the obtained results to in vivo conditions, one could assume 
that fibroblasts are involved in inflammatory response in the development of psoriatic plaques, however not as most powerful participants, which seems to be in agreement with the literature data $[22,41,42]$.

We did not observe significant differences in cytokine release between fibroblasts obtained from healthy controls skin and fibroblasts from lesional psoriatic skin. Other authors also did not find difference in many aspects of normal and psoriatic fibroblasts [8]. But is it worth pointing out that fibroblasts from perilesional skin of psoriatic plaques demonstrated significant differences in cytokine release compared to normal fibroblasts from healthy controls, which could suggest that direct surroundings of well-developed psoriatic plaques are already affected by pathological processes.

Among shortcoming of the present study one has to admit that unfortunately due to ethical reasons, measurements of interleukin levels in cell supernatants were performed only before the treatment. As for plasma level evaluation, two measurements were performed in a 3 -week interval. We could have expanded the time interval, however inpatient treatment usually does not last longer and we wanted the patients to adhere to the employed treatment as strictly as possible. Bearing in mind that about $30 \%$ to $40 \%$ of patients demonstrate nonadherence, evaluation of inpatients when they are separated from everyday worries and concentrated almost only on treatment issues is most desired and reliable $[43,44]$.

Worth mentioning is also one thing, that is, that extrapolation of the obtained results in vitro into in vivo conditions should be extremely cautiously performed. Direct and too brave conclusions could be difficult to draw and most confusing to compare with data obtained in different laboratory conditions. It could be argued that plasma levels of examined cytokines were already performed and published a few times but one has to bear in mind also the fact that cytokine evaluation results may vary due to different assays, individual variation in stage of the disease, demographic differences, and coexisting pathologies [29]. It should also be stressed that in context of fibroblasts, regarded as active participants of inflammatory response, the obtained results seem to be of value.

In conclusion, the obtained results confirm usefulness of plasma sIL-2R levels evaluation in monitoring psoriasis vulgaris activity during treatment. Additionally, they also support the notion that fibroblasts per se could be regarded as important elements of inflammatory reactions in human skin, however, they should rather not be treated as a major source of increased production of IL- 6 and IL-8 in psoriatic skin.

\section{ACKNOWLEDGMENTS}

This study was supported by the Grant from the Scientific Research Council in Warsaw (no 4PO5A 07918) and Medical University of Łódź Grants (no 502-11-353 and no 503119-1). The authors would like to express great thanks to Ms. Bogumila Kolago and Ms. Aleksandra Slusarczyk for preparation of fibroblast cultures.

\section{REFERENCES}

[1] Baker BS, Swain AF, Valdimarsson H, Fry L. T-cell subpopulations in the blood and skin of patients with psoriasis. British Journal of Dermatology. 1984;110(1):37-44.

[2] Griffiths CE, Voorhees JJ. Immunological mechanisms involved in psoriasis. Springer Seminars in Immunopathology. 1992;13(3-4):441-454.

[3] Kapp A. The role of cytokines for the pathogenesis of psoriasis. Der Hautarzt; Zeitschrift für Dermatologie, Venerologie, und verwandte Gebiete. 1993;44(4):201-207.

[4] Schon MP, Boehncke WH. Psoriasis. The New England Journal of Medicine. 2005;352(18):1899-1912.

[5] Smith TJ. Insights into the role of fibroblasts in human autoimmune diseases. Clinical and Experimental Immunology. 2005;141(3):388-397.

[6] Buckley CD, Pilling D, Lord JM, Akbar AN, Scheel-Toellner D, Salmon M. Fibroblasts regulate the switch from acute resolving to chronic persistent inflammation. Trends in Immunology. 2001;22(4):199-204.

[7] Prens EP, Benne K, van Damme J, et al. Interleukin-1 and interleukin-6 in psoriasis. The Journal of Investigative Dermatology. 1990;95(6 suppl):121S-124S.

[8] Debets R, Hegmans JPJJ, Deleuran M, Hooft S, Benner R, Prens EP. Expression of cytokines and their receptors by psoriatic fibroblast. I. Altered IL-6 synthesis. Cytokine. 1996;8(1):70-79.

[9] Borden EC, Chin P. Interleukin-6: a cytokine with potential diagnostic and therapeutic roles. The Journal of Laboratory and Clinical Medicine. 1994;123(6):824-829.

[10] Castells-Rodellas A, Castell JV, Ramirez-Bosca A, Nicolas JF, Valcuende-Cavero F, Thivolet J. Interleukin-6 in normal skin and psoriasis. Acta Dermato-Venereologica. 1992;72(3):165168.

[11] Elder JT, Sartor CI, Boman DK, Benrazavi S, Fisher GJ, Pittelkow MR. Interleukin-6 in psoriasis: expression and mitogenicity studies. Archives of Dermatological Research. 1992;284(6):324-332.

[12] Nickoloff BJ, Karabin GD, Barker JNWN, et al. Cellular localization of interleukin- 8 and its inducer, tumor necrosis factor-alpha in psoriasis. The American Journal of Pathology. 1991;138(1):129-140.

[13] Gearing AJ, Fincham NJ, Bird CR, et al. Cytokines in skin lesions of psoriasis. Cytokine. 1990;2(1):68-75.

[14] Fredriksson T, Pettersson U. Severe psoriasis—oral therapy with a new retinoid. Dermatologica. 1978;157(4):238-244.

[15] Schmitt J, Wozel G. The psoriasis area and severity index is the adequate criterion to define severity in chronic plaque-type psoriasis. Dermatology. 2005;210(3):194-199.

[16] Kemmett D, Symons JA, Colver GB, Duff GW. Serum-soluble interleukin 2 receptor in psoriasis. Failure to reflect clinical improvement. Acta Dermato-Venereologica. 1990;70(3):264266.

[17] Bonifati C, Ameglio F. Cytokines in psoriasis. International Journal of Dermatology. 1999;38(4):241-251.

[18] Lee RE, Gaspari AA, Lotze MT, Chang AE, Rosenberg SA. Interleukin 2 and psoriasis. Archives of Dermatology. 1988;124(12):1811-1815.

[19] Chodorowska G. Plasma concentrations of IFN- $\gamma$ and TNF$\alpha$ in psoriatic patients before and after local treatment with dithranol ointment. Journal of the European Academy of Dermatology and Venereology: JEADV. 1998;10(2):147-151.

[20] Smith RS, Smith TJ, Blieden TM, Phipps RP. Fibroblasts as sentinel cells. Synthesis of chemokines and regulation 
of inflammation. The American Journal of Pathology. 1997; 151(2):317-322.

[21] Zalewska A, Bowszyc-Dmochowska M, DziankowskaBarkowiak B, Bratos R, Sysa-Jedrzejowska A. Increased accumulation of fibroblasts in the dermis of psoriatic patients. The Journal of Investigative Dermatology. 2000;115:583.

[22] Kovacs D, Falchi M, Cardinali G, et al. Immunohistochemical analysis of keratinocyte growth factor and fibroblast growth factor 10 expression in psoriasis. Experimental Dermatology. 2005;14(2):130-137.

[23] Kapp A, Piskorski A, Schopf E. Elevated levels of interleukin 2 receptor in sera of patients with atopic dermatitis and psoriasis. British Journal of Dermatology. 1988;119(6):707-710.

[24] Oxholm A, Oxholm P, Staberg B, Bendtzen K. Interleukin6 in the epidermis of patients with psoriasis before and during PUVA treatment. Acta Dermato-Venereologica. 1989;69(3):195-199.

[25] Carducci M, Mussi A, Bonifati C, Fazio M, Ameglio F. sICAM1 , sIL-2R and beta 2-microglobulin serum levels in patients affected with psoriasis: relationship with disease severity. Archives of Dermatological Research. 1994;286(7):420-422.

[26] Mrowietz U, Jessat H, Schwarz A, Schwarz T. Anthralin (dithranol) in vitro inhibits human monocytes to secrete IL-6, IL-8 and TNF-alpha, but not IL-1. British Journal of Dermatology. 1997;136(4):542-547.

[27] Betti R, Rosti A, Lodi A, et al. Effect of UVB plus tar therapy on serum levels of interleukin-2 receptors in patients with psoriasis. Clinical and Experimental Dermatology. 1991;16(5):364366.

[28] Mussi A, Bonifati C, Carducci M, et al. Serum TNF-alpha levels correlate with disease severity and are reduced by effective therapy in plaque-type psoriasis. Journal of Biological Regulators \& Homeostatic Agents. 1997;11(3):115-118.

[29] Ameglio F, Bonifati C, Pietravalle M, Fazio M. Interleukin-6 and tumour necrosis factor levels decrease in the suction blister fluids of psoriatic patients during effective therapy. Dermatology. 1994;189(4):359-363.

[30] Bonifati C, Carducci M, Cordiali Fei P, et al. Correlated increases of tumour necrosis factor-alpha, interleukin-6 and granulocyte monocyte-colony stimulating factor levels in suction blister fluids and sera of psoriatic patients-relationships with disease severity. Clinical and Experimental Dermatology. 1994;19(5):383-387.

[31] Bonifati C, Solmone M, Trento E, Pietravalle M, Fazio M, Ameglio F. Serum interleukin-6 levels as an early marker of therapeutic response to UVB radiation and topical steroids in psoriatic patients. International Journal of Clinical \& Laboratory Research. 1994;24(2):122-123.

[32] Bonifati C, Carducci M, Mussi A, D’auria L, Ameglio F. IL-1 alpha, IL-1 beta and psoriasis: conflicting results in the literature. Opposite behaviour of the two cytokines in lesional or non-lesional extracts of whole skin. Journal of Biological Regulators \& Homeostatic Agents. 1997;11(4):133-136.

[33] Abanmi A, Al Harthi F, Al Agla R, Khan HA, Tariq M. Serum levels of proinflammatory cytokines in psoriasis patients from Saudi Arabia. International Journal of Dermatology. 2005;44(1):82-83.

[34] Naldi L. A new era in the management of psoriasis? Promises and facts. Dermatology. 2005;210(3):179-181.

[35] Hettmannsperger U, Detmar M, Owsianowski M, Tenorio S, Kammler HJ, Orfanos CE. Cytokine-stimulated human dermal microvascular endothelial cells produce interleukin 6 inhibition by hydrocortisone, dexamethasone, and calcitriol. The Journal of Investigative Dermatology. 1992;99(5):531-536.
[36] Ohta Y, Katayama I, Funato T, et al. In situ expression of messenger RNA of interleukin-1 and interleukin- 6 in psoriasis: interleukin-6 involved in formation of psoriatic lesions. Archives of Dermatological Research. 1991;283(6):351-356.

[37] Neuner P, Urbanski A, Trautinger F, et al. Increased IL-6 production by monocytes and keratinocytes in patients with psoriasis. The Journal of Investigative Dermatology. 1991;97(1):2733.

[38] Yoshinaga Y, Higaki M, Terajima S, et al. Detection of inflammatory cytokines in psoriatic skin. Archives of Dermatological Research. 1995;287(2):158-164.

[39] Biasi D, Carletto A, Caramaschi P, et al. Neutrophil functions and IL-8 in psoriatic arthritis and in cutaneous psoriasis. Inflammation. 1998;22(5):533-543.

[40] Grossman RM, Krueger J, Yourish D, et al. Interleukin 6 is expressed in high levels in psoriatic skin and stimulates proliferation of cultured human keratinocytes. Proceedings of the National Academy of Sciences of the United States of America. 1989;86(16):6367-6371.

[41] Myokai F, Koyama E, Nishikawa K, Noji S, Murayama Y, Taniguchi S. Aspects of interleukin-8 gene expression by gingival and dermal fibroblasts stimulated with interleukin-1beta or tumour necrosis factor alpha. Journal of the International Academy of Periodontology. 2004;6(1):21-28.

[42] Johansen C, Flindt E, Kragballe K, et al. Inverse regulation of the nuclear factor-kappaB binding to the p53 and interleukin8 kappaB response elements in lesional psoriatic skin. The Journal of Investigative Dermatology. 2005;124(6):1284-1292.

[43] Carroll CL, Feldman SR, Camacho FT, Balkrishnan R. Better medication adherence results in greater improvement in severity of psoriasis. British Journal of Dermatology. 2004;151(4):895-897.

[44] Zaghloul SS, Goodfield MJ. Objective assessment of compliance with psoriasis treatment. Archives of Dermatology. 2004;140(4):408-414. 


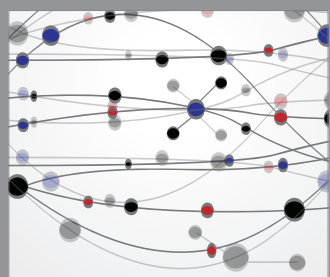

The Scientific World Journal
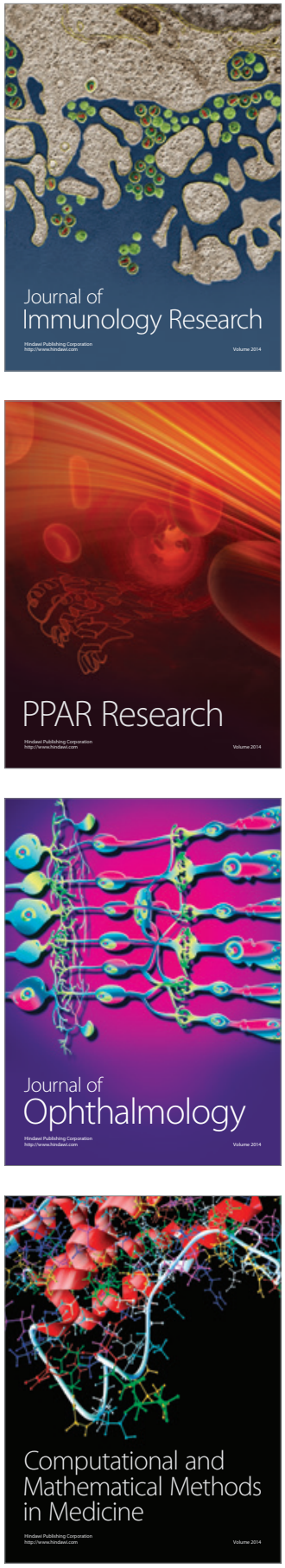

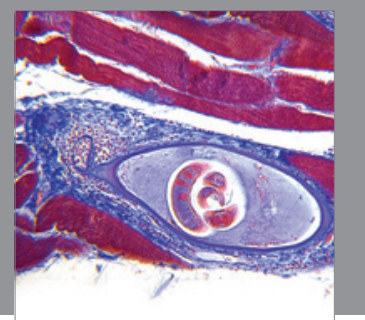

Gastroenterology

Research and Practice
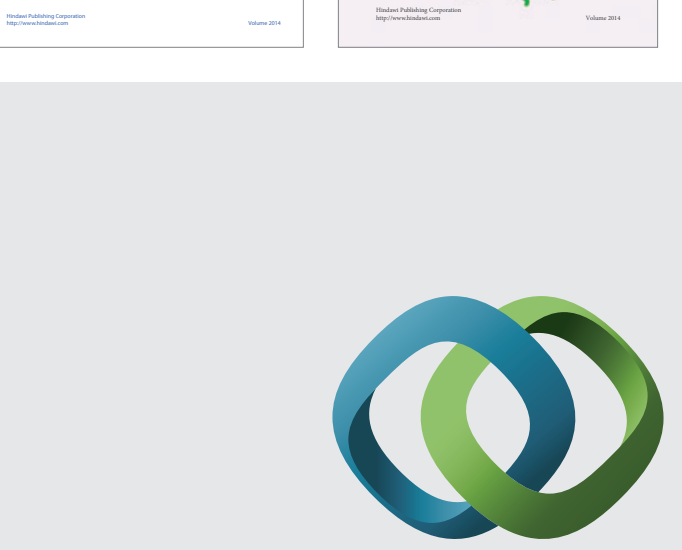

\section{Hindawi}

Submit your manuscripts at

http://www.hindawi.com
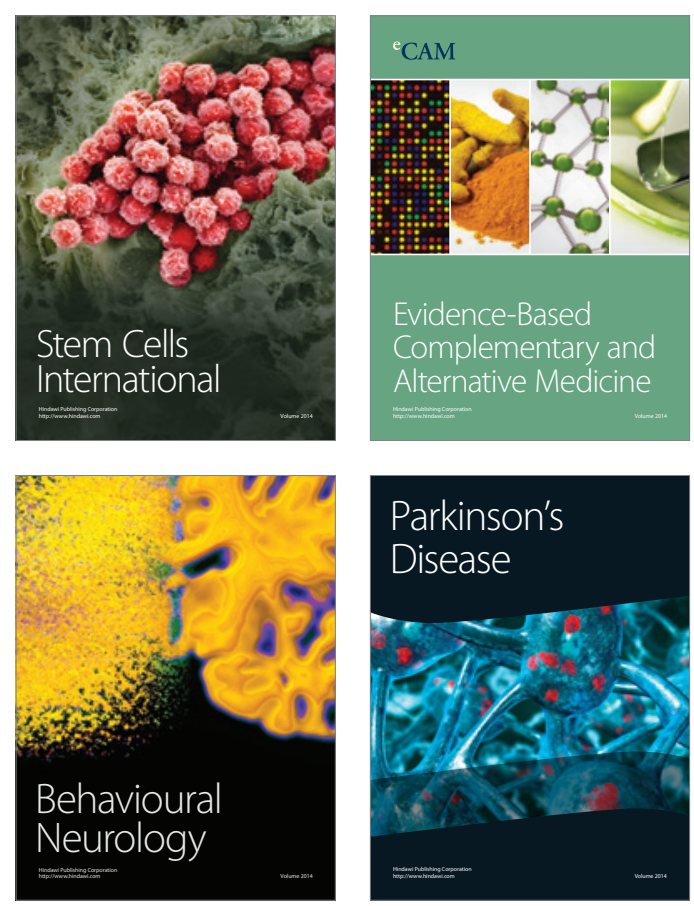

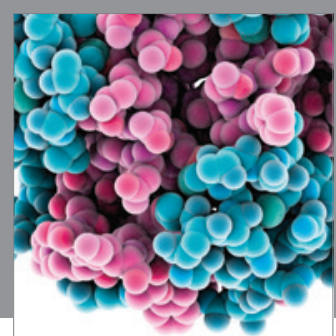

Journal of
Diabetes Research

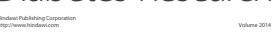

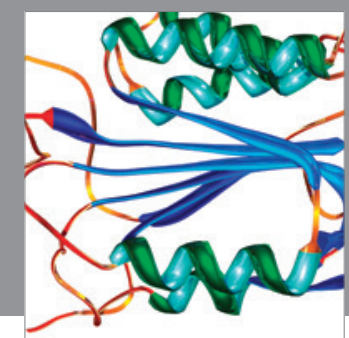

Disease Markers
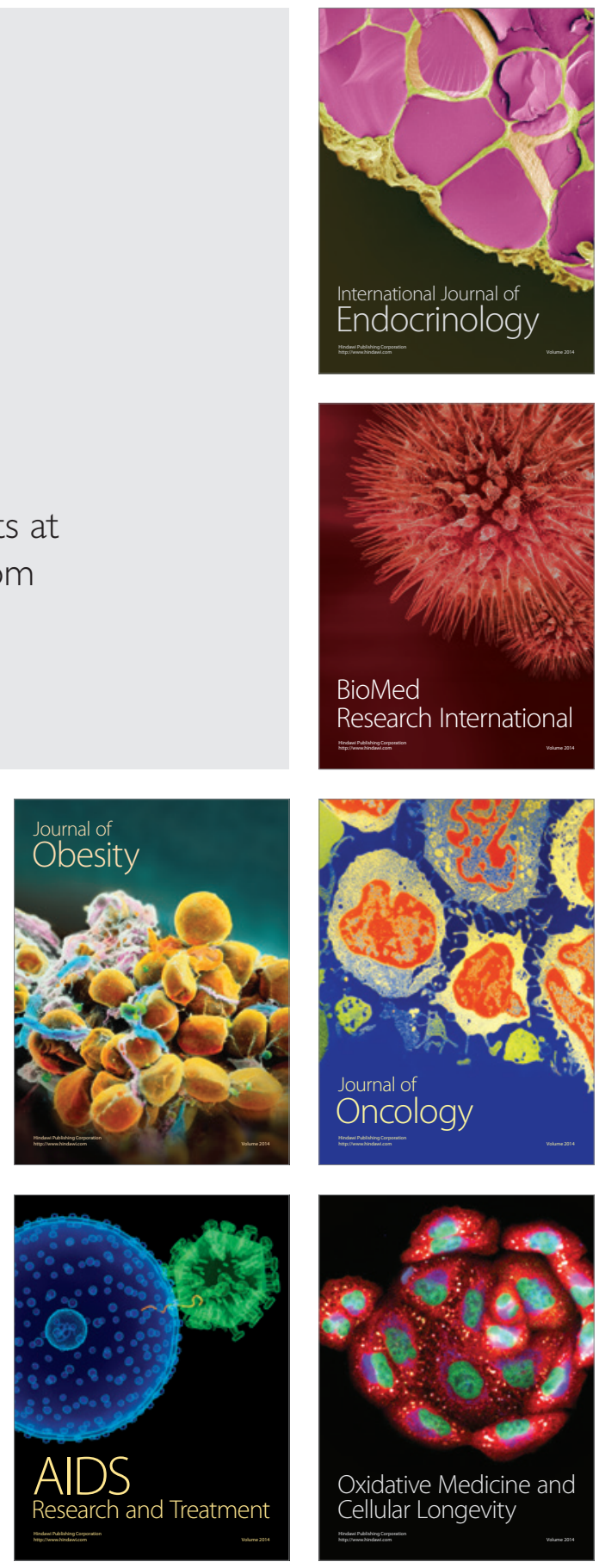